\title{
Cultivo de Tillandsia kautskyi E. Pereira, bromélia brasileira em risco de extinção: comparação de substratos
}

\author{
MARIA ESMERALDA SOARES PAYÃO DEMATTÊ
}

\begin{abstract}
RESUMO
Pouco se conhece sobre métodos para cultivo de Tillandsia kautskyi. Este estudo teve o objetivo de observar o desenvolvimento de plantas dessa espécie em substratos de origem vegetal, tendo como padrão uma mistura contendo xaxim. O experimento foi conduzido entre dezembro de 2000 e abril de 2002, em Jaboticabal (SP), em casa de vegetação com $70 \%$ de interceptação da luz solar. As mudas foram cultivadas em vasos plásticos, preenchidos com diferentes substratos: $\mathrm{S} 1=45 \%$ de xaxim $+45 \%$ de fibra de coco $+10 \%$ de húmus de minhoca; S2 $=45 \%$ de fibra de coco $+45 \%$ de casca de Pinus $+10 \%$ de húmus de minhoca; S3 $=100 \%$ de fibra de coco com adição de macro e micronutrientes; $\mathrm{S} 4=100 \%$ de fibra de coco. Houve diferença significativa apenas para o desenvolvimento do sistema radicular, maior em S3 do que em S2. Cálculos de regressão linear indicaram que as causas prováveis do menor desenvolvimento das raízes em S2 foram: maior densidade desse substrato, menor teor de matéria orgânica total, menor umidade natural, menores teores de potássio e boro, e concentrações mais altas (possivelmente tóxicas) de fósforo $\left(0,19 \%\right.$ de $\left.\mathrm{P}_{2} \mathrm{O}_{5}\right)$, ferro $(42.086 \mathrm{mg} / \mathrm{kg})$ e manganês (385 mg/kg). Concluiu-se que T. kautskyi pode ser cultivada em substratos que não contêm xaxim, e que substrato constituído por $100 \%$ de fibra de coco é um bom substituto para misturas contendo xaxim.
\end{abstract}

Palavras-chave: Tillandsia kautskyi, Bromeliaceae, bromélias, substrato, xaxim.

\begin{abstract}
Cultivation of Tillandsia kautskyi E. Pereira, an endangered Brazilian bromeliad: comparison of growing media. Very little is known about methods for cultivation of Tillandsia kautskyi. This study was aimed to compare the growth of $T$. kautskyi plants in different growing media of vegetal origin, using a mixture containing tree fern fiber as control. The experiment was carried out from December 2000 through April 2002, in Jaboticabal, state of São Paulo, Brazil, in a greenhouse $70 \%$ shaded. Seedlings were planted in plastic pots filled with the following growing media: $\mathrm{S} 1=45 \%$ of tree fern fiber $+45 \%$ of coconut husk $+10 \%$ of earthworm humus; S2 $=45 \%$ of coconut husk $+45 \%$ of Pinus bark $+10 \%$ of earthworm humus; S3 $=100 \%$ of coconut husk with addition of macro and micronutrients; S4 $=100 \%$ of coconut husk. Significant difference was found only for the root system development, larger in S3 than in S2. Calculations of linear regression have indicated that the probable causes of the poor root development in S2 were the higher density of this substrate, lower percentage of total organic matter, lower natural humidity, lower levels of potassium and boron, and higher concentrations, probably toxic, of phosphorus $\left(0.19 \%\right.$ of $\left.\mathrm{P}_{2} \mathrm{O}_{5}\right)$, iron $(42086 \mathrm{mg} / \mathrm{kg})$ and manganese $(385 \mathrm{mg} / \mathrm{kg})$. It was concluded that $T$. kautskyi plants can be grown in growing medium without tree fern fiber, and the coconut husk is a good substitute for mixtures containing tree fern fiber.
\end{abstract}

Keywords: Tillandsia kautskyi, Bromeliaceae, bromeliads, substrate, tree fern fiber

\section{INTRODUÇÃO}

Muitas espécies de Bromeliaceae distribuem-se em áreas restritas, o que coloca em perigo sua sobrevivência. Uma delas é Tillandsia kautskyi E. Pereira (Figura 1), listada pela Convention on International Trade in Endangered Species of Wild Fauna and Flora (CITES, 2001) como em risco de extinção.

PEREIRA (1974) classificou T. kautskyi no subgênero Anoplophytum e a descreveu como epífita acaule, totalmente acinzentada, florífera, com $8 \mathrm{~cm}$ de altura; folhas recurvadas, densamente imbricadas, ápice estreito; escapo com $4 \mathrm{~cm}$ de altura, glabro e esverdeado, com brácteas de $25 \mathrm{~mm}$ de comprimento; inflorescência

${ }^{1}$ Departamento de Produção Vegetal, Faculdade de Ciências Agrárias e Veterinárias, Unesp, Campus de Jaboticabal. Via de Acesso Prof. Paulo Donato Castellane, s/n, CEP 14884-900, Jaboticabal (SP), Brasil. Bolsista do CNPq. E-mail: inga.ambiental@ netsite.com.br com 12 flores, composta, com $3 \mathrm{~cm}$ de comprimento e 2 $\mathrm{cm}$ de diâmetro, superando o ápice das folhas; brácteas primárias ovadas, com $16 \mathrm{~mm}$ de comprimento e $14 \mathrm{~mm}$ de largura, longo-acuminadas; flores eretas com $2 \mathrm{~cm}$ de comprimento, sésseis. Suas inflorescências apresentam tonalidade rosada.

A T. kautskyi tem afinidade com as espécies brasileiras T. sprengeliana Kl. ex Mez e T. brachyphylla Baker (PEREIRA, 1974), ambas também ameaçadas de extinção (BASE DE DADOS TROPICAL, 2001). Diferencia-se de T. brachyphylla pela concrescência das sépalas, e de T. sprengeliana, por apresentar inflorescência composta e escamas não-pruinosas (PEREIRA, 1974).

A bromélia T. kautskyi foi descoberta em Domingos Martins, Estado do Espírito Santo, por Roberto 


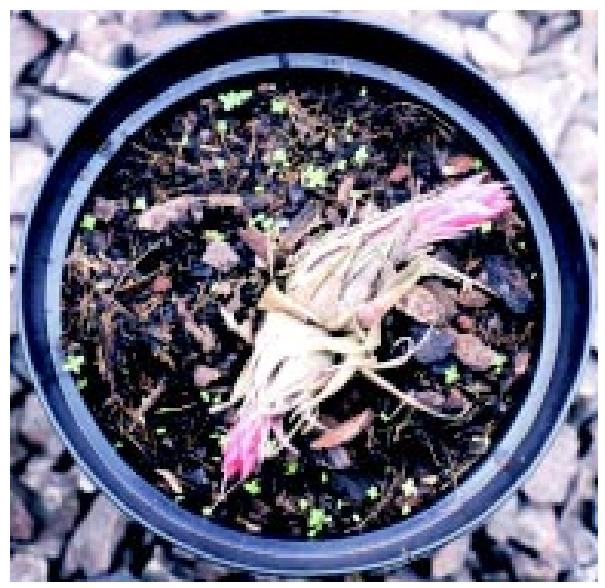

Figura 1. Tillandsia kautskyi E. Pereira (Bromeliaceae): plantas com inflorescência. (Vaso com 14,5 cm de diâmetro na parte superior; foto de M. E. S. P. Demattê).

A. Kautsky, em 1973 (PEREIRA, 1974; SILVA \& COUTINHO, 1999). Além do risco representado por seu habitat restrito, é uma planta de crescimento lento e não foi encontrada entre as bromélias cultivadas pelos principais produtores do Brasil (ANDRADE \& DEMATTÊ, 1999). Pouco se conhece sobre métodos para seu cultivo, considerado difícil.

A maioria dos produtores brasileiros cultiva bromélias em substratos que contêm xaxim (ANDRADE \& DEMATTÊ, 1999), constituído pelo pseudocaule fibroso retirado de espécies nativas de Dicksoniaceae e Cyatheaceae, especialmente a samambaia-açu (Dicksonia sellowiana Presl. Hook), espécie produtora do xaxim verdadeiro e ameaçada de extinção. Recentemente, a extração e exploração de Dicksonia sellowiana foram proibidas em todo o território nacional, de acordo com a Resolução Conama 278/1 de 24 de maio de 2001 (RESOLUÇÕES, 2005).

Considerando a necessidade de se estabelecer métodos de cultivo que contribuam para a conservação de Tillandsia kautskyi e de buscar alternativas ao uso do xaxim, este trabalho teve o objetivo de comparar o desenvolvimento dessa bromélia em diferentes substratos de origem vegetal.

\section{MATERIAL E MÉTODOS}

O experimento foi conduzido em Jaboticabal-SP $\left(21^{\circ} 15^{\prime}\right.$ de latitude sul e $48^{\circ} 15^{\prime}$ de longitude oeste), local de ocorrência de bromélias (PINTO et al., 1994 e 1995) e de condições favoráveis ao seu cultivo.

Os valores médios de temperatura e umidade relativa do ar em Jaboticabal, no período de 1971 a 2000, foram de $22,2^{\circ} \mathrm{Ce} 70,8 \%$, respectivamente, sendo fevereiro e outubro os meses mais quentes (média de $20,6^{\circ} \mathrm{C}$ ), e julho, o mês mais frio (média de $12,5^{\circ} \mathrm{C}$ ); a média da precipitação total anual, no mesmo período, foi de 1.424,6 mm (UNESP, 2004). O fotoperíodo local varia das $10 \mathrm{~h} 50$ às $13 \mathrm{~h} 26$ (Prof. Dr. Clovis Alberto Volpe, comunicação pessoal). A altitude local é de aproximadamente 560 metros.

As plantas da espécie estudada, Tillandsia kautskyi E. Pereira, eram procedentes do Orquidário Binot, Petrópolis (RJ), e foram cultivadas no Viveiro Experimental de Plantas Ornamentais e Florestais, Câmpus de Jaboticabal da
Universidade Estadual Paulista (Unesp), em casa de vegetação (telado) com $70 \%$ de interceptação da luz solar, resultando em iluminância de 20.000 a 40.000 lux.

As mudas foram plantadas em vasos plásticos pretos com 14,5 cm de diâmetro superior, $11,0 \mathrm{~cm}$ de diâmetro inferior e $11,0 \mathrm{~cm}$ de altura. Apesar de o cultivo em vasos não ser recomendado para plantas do gênero Tillandsia, especialmente as que apresentam folhas duras de cor cinza (PAULA \& SILVA, 2001; BROMELIAD SOCIETY INTERNATIONAL, 2005; SOCIEDADE BRASILEIRA DE BROMÉLIAS, 2005), este foi o método que possibilitou a sobrevivência dessas plantas no Viveiro Experimental, pois elas não se adaptaram ao cultivo em placas fibrosas.

O experimento foi conduzido entre dezembro de 2000 e abril de 2002, comparando-se os seguintes substratos: $\mathrm{S} 1=45 \%$ de xaxim $+45 \%$ de fibra de coco + $10 \%$ de húmus de minhoca; $\mathrm{S} 2=45 \%$ de fibra de coco + $45 \%$ de casca de Pinus $+10 \%$ de húmus de minhoca; $\mathrm{S} 3=$ $100 \%$ de fibra de coco com adição de macro e micronutrientes; $\mathrm{S} 4=100 \%$ de fibra de coco. Os substratos $\mathrm{S} 1$ e S2 foram os que proporcionaram os melhores resultados para cultivo de Aechmea fasciata Bak. em experimento de D'ANDRÉA \& DEMATTÊ (2000). Os substratos S3 e S4 são constituídos por $100 \%$ de fibra de Cocos nucifera L. e correspondem, respectivamente, às denominações técnicas iniciais (na fase experimental) de A-119 e A-121, da empresa Amafibra - Fibras e Substratos Agrícolas da Amazônia Ltda.; posteriormente, A-121 recebeu o nome comercial de Golden Mix Fibroso ${ }^{\circledR}$.

O delineamento de blocos casualizados foi utilizado, com nove repetições, sendo cada unidade experimental representada por um vaso com uma planta. As mudas foram distribuídas nos blocos por semelhança na altura, pois o lote não era uniforme e não havia outras mudas disponíveis em quantidade suficiente. Na ocasião do plantio, as raízes velhas das plantas foram deixadas somente até 3 cm de comprimento, cortando-se a parte restante.

Na ocasião do plantio, em 14-12-2000, as mudas apresentavam, em média, 27,4 folhas, $6,6 \mathrm{~cm}$ de altura da parte aérea e 2,7 cm de diâmetro máximo da parte aérea, sem diferenças significativas $(\mathrm{P}>0,05)$ dentro de blocos.

A irrigação foi fornecida por aspersão, de modo a umedecer completamente o substrato, a cada três dias. 
Durante a condução do experimento, as plantas não receberam adubação.

Foram feitas avaliações mensais do crescimento das plantas, considerando-se a altura, o diâmetro máximo da parte aérea e o número de folhas, além de registrada qualquer alteração na sua aparência.

No final do experimento, as plantas foram retiradas do substrato, anotando-se o número de raízes novas e o comprimento do sistema radicular. Foram atribuídas notas para o sistema radicular: zero = sem raízes; 1 a 4: valores comparativos para desenvolvimento do sistema radicular, menor em 1 e maior em 4.

Além disso, realizou-se a análise de propriedades físicas e químicas dos substratos comparados, no início e no final do experimento. As amostras representativas do estado inicial foram retiradas antes da instalação do experimento, uma para cada substrato. No final, também foi composta uma amostra por substrato, misturando-se as nove repetições.

Os valores obtidos nas avaliações das plantas foram submetidos à análise de variância e a cálculos de regressão linear com os valores das variáveis referentes aos substratos.

\section{RESULTADOS E DISCUSSÃO}

Dentro do telado, as temperaturas máximas e mínimas mensais registradas durante o período de cultivo foram, respectivamente, de $42{ }^{\circ} \mathrm{C}$ (outubro de 2001) e 5 ${ }^{\circ} \mathrm{C}$ (junho de 2001). A umidade relativa do ar foi sempre superior a $50 \%$.

Em setembro de 2001, 70\% das plantas exibiam inflorescências. As 30\% restantes não floresceram. Em outras localidades, a floração de T. kautskyi também ocorre, normalmente, em setembro (SILVA \& COUTINHO, 1999).

Até o final do experimento, não foram detectadas, pela análise de variância, diferenças significativas $(\mathrm{P}>0,05)$ entre as variáveis de crescimento da parte aérea das plantas nos diferentes substratos (Tabela 1). As maiores médias de altura e diâmetro máximo foram atingidas em outubro de 2001; posteriormente, a parte aérea de algumas plantas apresentou dimensões menores, em conseqüência de murchamento ou secamento de folhas. Esse processo de senescência é normal em bromélias depois do florescimento.

Tabela 1. Valores máximos atingidos por variáveis referentes à parte aérea de plantas ${ }^{(1)}$ de Tillandsia kautskyi E. Pereira cultivadas em diferentes substratos. Jaboticabal (SP), dezembro de 2000 a abril de 2002.

\begin{tabular}{cccccc}
\hline Substratos $^{(2)}$ & $\begin{array}{c}\text { Número de } \\
\text { folhas }^{(3)}\end{array}$ & $\begin{array}{c}\text { Altura da parte } \\
\text { aérea }(\mathrm{cm})\end{array}$ & $\begin{array}{c}\text { Diâmetro máximo } \\
\text { da parte aérea }(\mathrm{cm})\end{array}$ & $\begin{array}{c}\text { Número de } \\
\text { inflorescências }^{(3)}\end{array}$ & $\begin{array}{c}\text { Número de } \\
\text { brotos }^{(3)}\end{array}$ \\
\hline S1 & 40,0 & 7,6 & 6,0 & 0,9 & 0,6 \\
S2 & 42,1 & 6,9 & 6,4 & 0,8 & 0,2 \\
S3 & 47,5 & 7,0 & 5,6 & 0,8 & 0,6 \\
S4 & 32,4 & 7,0 & 5,6 & 0,7 & 0,8 \\
F & $2,03 \mathrm{~ns}$ & $0,84 \mathrm{~ns}$ & $1,27 \mathrm{~ns}$ & $0,42 \mathrm{~ns}$ & $0,34 \mathrm{~ns}$ \\
$\mathrm{CV}(\%)$ & 13,98 & 14,49 & 15,73 & 19,69 & 47,29 \\
\hline
\end{tabular}

${ }^{(1)}$ Média de 9 plantas. ${ }^{(2)} \mathrm{S} 1=45 \%$ de xaxim $+45 \%$ de fibra de coco $+10 \%$ de húmus de minhoca; $\mathrm{S} 2=45 \%$ de fibra de coco $+45 \%$ de casca de Pinus $+10 \%$ de húmus de minhoca; S3 = 100\% de fibra de coco com adição de macro e micronutrientes; S4 = 100\% de fibra de coco. ${ }^{(3)}$ Nesta tabela, são apresentados os dados originais; as análises de número de folhas foram feitas com valores transformados em $\sqrt{x}$, e as de número de inflorescências e número de brotos, em $\sqrt{x+0,5} \cdot \mathrm{CV}=$ Coeficiente de variação.

Por serem as folhas muito imbricadas e sobrepostas, sua contagem foi difícil. Muitas vezes, para não causar danos às plantas, o número de folhas teve de ser estimado e, portanto, não é um bom parâmetro para avaliação do crescimento de T. kautskyi.

Em todos os substratos, a aparência das plantas, no final, não era boa, observando-se folhas murchas ou secas e ataque moderado de cochonilhas. Na maioria dos casos, isso pode ser atribuído à senescência natural após o florescimento, mas algumas plantas não floresceram. Houve morte de uma planta (sem florescimento) no substrato S2, em setembro de 2001, e duas em S4 (uma sem florescimento e outra após florescer), em março de
2002. As temperaturas máximas no local de cultivo podem ter sido prejudiciais ao desenvolvimento das plantas, pois um lote de plantas da mesma espécie, que não fazia parte do experimento, crescendo em lugar onde as temperaturas foram mais baixas, apresentava melhor aparência.

Em relação ao sistema radicular (Tabela 2), apenas os valores da avaliação por notas permitiram a confirmação estatística de que o crescimento das raízes no substrato $\mathrm{S} 2$ foi menor. Também para plantas de Tillandsia gardneri Lindl., cultivadas nos mesmos substratos, DEMATTÊ (2003) verificou menor desenvolvimento do sistema radicular no tratamento correspondente a S2. 
Tabela 2. Médias dos valores obtidos na avaliação das raízes de plantas ${ }^{(1)}$ de Tillandsia kautskyi E. Pereira cultivadas em diferentes substratos. Jaboticabal (SP), dezembro de 2000 a abril de 2002.

\begin{tabular}{|c|c|c|c|}
\hline Substratos $^{(2)}$ & $\begin{array}{c}\text { Número de raízes } \\
\text { de primeira ordem } \\
(3,4)\end{array}$ & $\begin{array}{l}\text { Comprimento da raiz mais } \\
\text { longa }(\mathrm{cm})^{(3)}\end{array}$ & $\begin{array}{c}\text { Nota atribuída ao } \\
\text { sistema radicular }^{(3,5)}\end{array}$ \\
\hline $\mathrm{S} 1$ & 4,8 & 8,5 & $1,0 \mathrm{ab}$ \\
\hline $\mathrm{S} 2$ & 2,8 & 5,6 & $0,7 \mathrm{~b}$ \\
\hline $\mathrm{S} 3$ & 4,6 & 7,3 & $2,0 \mathrm{a}$ \\
\hline $\mathrm{S} 4$ & 4,6 & 7,2 & $1,1 \mathrm{ab}$ \\
\hline $\mathrm{F}$ & $1,62 \mathrm{~ns}$ & $1,21 \mathrm{~ns}$ & $3,77 *$ \\
\hline $\mathrm{CV}(\%)$ & 24,67 & 25,66 & 22,59 \\
\hline
\end{tabular}

${ }^{(1)}$ Média de 9 plantas.

${ }^{(2)} \mathrm{S} 1=45 \%$ de xaxim $+45 \%$ de fibra de coco $+10 \%$ de húmus de minhoca; $\mathrm{S} 2=45 \%$ de fibra de coco $+45 \%$ de casca de Pinus $+10 \%$ de húmus de minhoca; S3 = 100\% de fibra de coco com adição de macro e micronutrientes; S4 = 100\% de fibra de coco.

(3) Nesta tabela, são apresentados os dados originais; as análises de número de raízes de primeira ordem, comprimento da raiz mais longa e nota atribuída ao sistema radicular foram feitas com dados transformados em $\sqrt{x+0,5}$

(4) Raízes que dão origem às ramificações.

(5) zero = sem raízes; 1 a 4: notas comparativas para desenvolvimento do sistema radicular, menor em 1 e maior em 4. ns $=$ não-significativo a $5 \%$ de probabilidade $; *$ = significativo a $5 \%$ de probabilidade .

$\mathrm{CV}=$ Coeficiente de variação.

Médias acompanhadas de letras distintas, na coluna, diferem entre si a 5\% de probabilidade pelo teste de Tukey.

Valores de pH entre 3,5 e 4,5 são considerados ideais às bromélias (BAENSCH \& BAENSCH, 1994). Inicialmente, o $\mathrm{pH}$ de todos os substratos esteve dentro dessa faixa, mas, no final do experimento, S1 e S4 apresentavam $\mathrm{pH}$ mais alto que o recomendado (Tabela 3).

Tabela 3. Propriedades físicas e químicas dos substratos estudados. Análise específica para substratos, realizada pelo laboratório do Departamento de Solos e Nutrição de Plantas da Escola Superior de Agricultura "Luiz de Queiroz", Piracicaba (SP). ${ }^{(1)}$

\begin{tabular}{|c|c|c|c|c|}
\hline Substratos $^{(2)}$ & $\mathrm{pH}$ em $\mathrm{CaCl}_{2} 0,01 \mathrm{M}^{(3)}$ & Densidade $\left(\mathrm{g} / \mathrm{cm}^{3}\right)^{(4)}$ & Umidade total $(\%)^{(4)}$ & $\begin{array}{l}\text { Matéria orgânica total } \\
\left(\text { combustão) }(\%)^{(5)}\right.\end{array}$ \\
\hline S1 inicial & 4,0 & 0,29 & 10,88 & 64,01 \\
\hline S1 final & 4,9 & 0,25 & 14,02 & 85,52 \\
\hline S2 inicial & 3,9 & 0,40 & 9,46 & 55,09 \\
\hline S2 final & 4,2 & 0,45 & 8,79 & 53,48 \\
\hline S3 inicial & 3,9 & 0,18 & 13,57 & 94,19 \\
\hline S3 final & 4,3 & 0,14 & 14,16 & 93,55 \\
\hline S4 inicial & 4,0 & 0,10 & 15,44 & 91,58 \\
\hline S4 final & 4,9 & 0,15 & 13,52 & 94,09 \\
\hline
\end{tabular}

(1) Os valores de cada linha correspondem a uma amostra.

${ }^{(2)} \mathrm{S} 1=45 \%$ de xaxim $+45 \%$ de fibra de coco $+10 \%$ de húmus de minhoca; $\mathrm{S} 2=45 \%$ de fibra de coco $+45 \%$ de casca de Pinus + $10 \%$ de húmus de minhoca; $\mathrm{S} 3=100 \%$ de fibra de coco com adição de macro e micronutrientes; $\mathrm{S} 4=100 \%$ de fibra de coco; inicial = substrato antes da utilização; final = substrato coletado nos vasos no final do experimento.

(3) Com umidade natural; avaliado na diluição de 1:5 (10 g de substrato em $50 \mathrm{~g} \mathrm{de} \mathrm{CaCl}_{2}$ ).

(4) Com umidade natural.

${ }^{(5)} \mathrm{Em}$ base seca $\left(110^{\circ} \mathrm{C}\right)$.

As análises químicas dos substratos comparados (Tabela 4) mostraram valores próximos para S3 e S4, exceto quanto à concentração de sódio, acentuadamente mais alta em S3. A adição de macro e micronutrientes a S3, informada pela empresa fabricante, não se refletiu em teores mais altos para a maioria dos outros nutrientes analisados; apenas cálcio, magnésio, enxofre e cobre apresentaram concentrações um pouco maiores em S3 do que em S4. 
Tabela 4. Concentrações totais de macro e micronutrientes nos substratos estudados (base seca, $110^{\circ} \mathrm{C}$ ). Análise específica para substratos, realizada pelo laboratório do Departamento de Solos e Nutrição de Plantas da Escola Superior de Agricultura "Luiz de Queiroz", Piracicaba (SP). ${ }^{(1)}$

\begin{tabular}{|c|c|c|c|c|c|c|c|c|c|c|c|c|}
\hline \multirow{2}{*}{ Substratos $^{(2)}$} & \multicolumn{6}{|c|}{$\begin{array}{c}\text { Macronutrientes } \\
(\%)\end{array}$} & \multicolumn{6}{|c|}{$\begin{array}{l}\text { Micronutrientes } \\
(\mathrm{mg} / \mathrm{kg})\end{array}$} \\
\hline & $\mathrm{N}$ & $\mathrm{P}_{2} \mathrm{O}_{5}$ & $\mathrm{~K}_{2} \mathrm{O}$ & $\mathrm{Ca}$ & $\mathrm{Mg}$ & $S$ & $\mathrm{Cu}$ & $\mathrm{Fe}$ & $\mathrm{Mn}$ & $\mathrm{Zn}$ & B & $\mathrm{Na}$ \\
\hline S1 inicial & 0,89 & 0,21 & 0,44 & 0,18 & 0,15 & 0,10 & 55 & 39.780 & 384 & 116 & 10 & 1.096 \\
\hline S1 final & 1,36 & 0,09 & 0,05 & 1,59 & 0,24 & 0,03 & 35 & 10.518 & 124 & 70 & 13 & 497 \\
\hline S2 inicial & 0,59 & 0,19 & 0,22 & 0,21 & 0,10 & 0,04 & 34 & 42.086 & 385 & 57 & 7 & 1.205 \\
\hline S2 final & 0,73 & 0,20 & 0,02 & 0,60 & 0,12 & 0,03 & 23 & 26.758 & 186 & 53 & 8 & 302 \\
\hline S3 inicial & 0,60 & 0,03 & 1,28 & 0,17 & 0,14 & 0,08 & 14 & 5.860 & 47 & 78 & 28 & 1.164 \\
\hline S3 final & 0,68 & 0,03 & 0,05 & 1,34 & 0,12 & 0,05 & 6 & 5.870 & 43 & 72 & 19 & 495 \\
\hline S4 inicial & 0,60 & 0,04 & 1,30 & 0,15 & 0,13 & 0,04 & 13 & 6.753 & 48 & 111 & 33 & 497 \\
\hline S4 final & 0,75 & 0,03 & 0,02 & 1,26 & 0,13 & 0,08 & 6 & 5.220 & 30 & 69 & 19 & 310 \\
\hline
\end{tabular}

(1) Os valores de cada linha correspondem a uma amostra.

${ }^{(2)} \mathrm{S} 1=45 \%$ de xaxim $+45 \%$ de fibra de coco $+10 \%$ de húmus de minhoca; $\mathrm{S} 2=45 \%$ de fibra de coco $+45 \%$ de casca de Pinus + $10 \%$ de húmus de minhoca; S3 = 100\% de fibra de coco com adição de macro e micronutrientes; S4 = 100\% de fibra de coco; inicial = substrato antes da utilização; final = substrato coletado nos vasos no final do experimento.

Tratando-se de fornecimento de nutrientes a bromélias, a relação de 1:3 a 1:4 entre as concentrações de nitrogênio e potássio no fertilizante foi mencionada, por KÄMPF (1984), como ótima para cultivo de Aechmea fasciata Bak. Relações N:K de 1:1 (PAULA \& SILVA, 2001) e 1:2 (SILVA \& COUTINHO, 1999; PAULA \& SILVA, 2001) também têm sido recomendadas para bromélias. Para plantas do gênero Tillandsia, considerouse adequada a relação 1:2 (BROMELIA, 2005).

As relações mais aproximadas de 1:2 a 1:4 foram encontradas nos substratos S3 e S4 nas condições iniciais (Tabela 4). No final, todos os substratos haviam perdido grande quantidade de potássio e apresentaram teores semelhantes desse nutriente, sempre baixos. Além do potássio, os teores de cobre, manganês, zinco e sódio diminuíram com o tempo. Para os demais nutrientes, isso não ocorreu ou não foi claramente constatado.

Somente os resultados estatisticamente significativos das análises de regressão linear são apresentados (Tabela 5). Esses resultados indicaram prováveis causas do menor desenvolvimento das raízes em S2 (Tabela 5), necessitando de confirmação futura, pois os cálculos foram feitos com pequeno número de amostras. Entretanto, são aqui apresentados por serem coerentes com o que foi observado.

O substrato S2 apresentou maior densidade, menor umidade natural e menor teor de matéria orgânica total (Tabela 3), correlacionados com menor desenvolvimento das raízes (Tabela 5).

As concentrações de $\mathrm{K}_{2} \mathrm{O}$ e de boro mais baixas, encontradas em $\mathrm{S} 2$, corresponderam aos sistemas radiculares menos desenvolvidos, indicando efeito benéfico dos teores mais elevados desses nutrientes no substrato, dentro dos limites de variação verificados (Tabela 5).

Por outro lado, também houve correlações negativas entre concentrações de nutrientes no substrato e desenvolvimento do sistema radicular de T. kautskyi, dentro dos limites de variação (Tabela 5). As bromélias são plantas muito sensíveis ao excesso de nutrientes, mas as recomendações de cautela restringem-se à adubação foliar e às substâncias que atingem as folhas, por se considerar que as raízes têm importância secundária na absorção de nutrientes. A Sociedade Brasileira de Bromélias (JARDIM DE FLORES, 2005) tem alertado sobre o perigo da toxidez por cobre, que, mesmo em pequenas quantidades, pode levar à morte plantas dessa família, extremamente intolerantes a metais pesados (FLOWER, 2005). Até os fungicidas à base de cobre, manganês ou zinco são prejudiciais às bromélias (SCHUBERT, 1990; SILVA \& COUTINHO, 1999; FLOWER, 2005). De acordo com informações da Sociedade Brasileira de Bromélias (JARDIM DE FLORES, 2005), também o excesso de boro ou de fósforo causaria danos às bromélias, provocando queimaduras no ápice das folhas; não são citadas as concentrações em que cada nutriente se tornaria nocivo às plantas, mas no caso do boro, segundo a mesma fonte, sua adição deve ser evitada. O sódio é outro micronutriente que pode causar prejuízos a espécies vegetais (BECKERMAN, 2005); entre as espécies sensíveis ao excesso de sódio, estão as da família Bromeliaceae (AGGIE-HORTICULTURE, 2005).

Nesse experimento, conforme se observa na Tabela 4, os substratos S1 e S2 apresentaram os teores mais elevados de fósforo. As concentrações de cobre foram mais altas nos substratos S1 e S2, especialmente em S1. No início, S1 e S4 apresentaram concentrações mais elevadas de zinco, mas essas diferenças diminuíram no final do período de cultivo. Os teores mais altos de boro foram verificados em S3 e S4. Os substratos S1, S2 e S3 apresentaram, inicialmente, maiores concentrações de sódio que $\mathrm{S} 4$, porém, no final, as diferenças eram pequenas.

Os cálculos de regressão linear não detectaram efeito adverso dos teores mais elevados de cobre, zinco, 
boro e sódio no desenvolvimento das plantas de T. kautskyi, dentro dos limites de variação verificados, mas indicaram prejuízo causado pelas maiores concentrações de fósforo (Tabela 5).

Tabela 5. Resultados de cálculos de regressão linear entre notas atribuídas ao sistema radicular de plantas de Tillandsia kautskyi E. Pereira (X) e valores referentes a propriedades físicas e químicas do substrato de cultivo (Y).

\begin{tabular}{|c|c|c|c|c|}
\hline $\mathrm{X}$ & $\mathrm{Y}$ & Limites de variação & F (regressão linear) & $\mathrm{r}$ \\
\hline \multirow{10}{*}{$\begin{array}{l}\text { Nota para o } \\
\text { sistema } \\
\text { radicular }^{(1)}\end{array}$} & Densidade final $^{(2)}$ & 0,14 a $0,45 \mathrm{~g} / \mathrm{cm}^{3}$ & $8,06 * *$ & $-0,4864 * *$ \\
\hline & Umidade total inicial $(\%)^{(2)}$ & 9,46 a $15,44 \%$ & $4,62 *$ & $0,3886 *$ \\
\hline & Umidade total final $(\%)^{(2)}$ & 8,79 a $14,16 \%$ & $5,72 *$ & $0,4245 *$ \\
\hline & $\begin{array}{l}\text { Matéria orgânica total inicial } \\
\left(\text { combustão) }(\%)^{(3)}\right.\end{array}$ & 55,09 a $94,19 \%$ & $9,11 * *$ & $0,5093 * *$ \\
\hline & $\begin{array}{l}\text { Matéria orgânica total } \\
\text { final (combustão) }(\%)^{(3)}\end{array}$ & 53,48 a $94,09 \%$ & $7,03 *$ & $0,4614 *$ \\
\hline & $\mathrm{P}_{2} \mathrm{O}_{5}^{(4)}$ & 0,03 a $0,21 \%$ & $7,02 *$ & $-0,4612 *$ \\
\hline & $\mathrm{K}_{2} \mathrm{O}^{(4)}$ & 0,22 a $1,30 \%$ & $7,79 * *$ & $0,4803 * *$ \\
\hline & $\mathrm{Fe}^{(4)}$ & 5.860 a $42.086 \mathrm{mg} / \mathrm{kg}$ & $7,66 * *$ & $-0,4772 *$ \\
\hline & $\mathrm{Mn}^{(4)}$ & 47 a $385 \mathrm{mg} / \mathrm{kg}$ & $7,17 *$ & $-0,4650 *$ \\
\hline & $\mathrm{B}^{(4)}$ & 7 a $33 \mathrm{mg} / \mathrm{kg}$ & $5,62 *$ & $0,4215 *$ \\
\hline
\end{tabular}

\footnotetext{
(1) Zero = sem raízes; 1 a 4: notas comparativas para desenvolvimento do sistema radicular, menor em 1 e maior em 4.

${ }^{(2)}$ Com umidade natural.

${ }^{(3)} \mathrm{Em}$ base seca $\left(110^{\circ} \mathrm{C}\right)$.

${ }^{(4)}$ Concentração inicial no substrato.

$\mathrm{r}=$ coeficiente de correlação; *, **: significativo, respectivamente, a 5\% e 1\% de probabilidade pelos testes $\mathrm{F}$ (para regressão linear) e t (para r).
}

As concentrações de ferro e de manganês também foram mais altas nos substratos S1 e S2 (Tabela 4). Sobre o ferro, não foram encontradas menções, na literatura especializada, há um possível efeito nocivo desse íon em bromélias, mas os cálculos de regressão linear indicaram, no presente experimento, efeito prejudicial das maiores concentrações de ferro e de manganês sobre o desenvolvimento das raízes de T. kautskyi (Tabela 5), e, portanto, inadequação dos substratos S1 e S2 para o cultivo de plantas dessa espécie.

Muitos autores, entre os quais BENZING \& RENFROW (1980), afirmaram que as raízes de bromélias do gênero Tillandsia, se existirem, são usadas somente para fixação da planta no substrato. As tilândsias têm sido chamadas de "bromélias atmosféricas", porque absorvem água e nutrientes diretamente do ar, em vez de obtê-los do solo, do substrato ou de material orgânico armazenado na parte central da planta (tanque ou cisterna), como é o caso da maioria das bromélias epífitas (BENZING \& RENFROW, 1980). Segundo BENZING et al. (1976), a absorção de água e sais é feita, nas bromélias atmosféricas, por tricomas que revestem as folhas. Considerando essas informações, o indício do efeito de nutrientes do substrato sobre o crescimento de raízes de Tillandsia kautskyi (Tabela 5) merece destaque, porque, neste caso, estaria ocorrendo absorção de nutrientes também pelas raízes.

\section{CONCLUSÕES}

Tillandsia kautskyi pode ser cultivada em substratos sem xaxim.

Para cultivo dessa espécie, substrato constituído por $100 \%$ de fibra de coco é um substituto adequado de misturas contendo xaxim.

\section{AGRADECIMENTOS}

A autora agradece ao Orquidário Binot, Petrópolis (RJ), pela doação das plantas utilizadas nesse estudo; à Dra. Maria das Graças Lapa Wanderley, do Instituto de Botânica do Estado de São Paulo, pela identificação da espécie; ao Eng. Agr. Orlando Graeff, da Sociedade Brasileira de Bromélias, pela ajuda na obtenção das plantas e por informações fundamentais à pesquisa; ao Sr. Angelo Luis Malvestiti, pela gentileza em esclarecer questões referentes aos substratos; à Bióloga Ula Vidal do Valle Silva, pelas sugestões; ao CNPq, pelo apoio ao projeto.

\section{REFERÊNCIAS BIBLIOGRÁFICAS}

\section{AGGIE-HORTICULTURE. Bromeliaceae or pineapple} family. Disponível em: < http://aggiehorticulture.tamu.edu/syllabi/302/pine/pine.htm>. Acesso em: 17 fev. 2005. 
ANDRADE, F. S. A.; DEMATTÊ, M. E. S. P. Estudo sobre produção e comercialização de bromélias nas regiões Sul e Sudeste do Brasil. Revista Brasileira de Horticultura Ornamental, Campinas, v.5, p.97-110, 1999.

BAENSCH, U.; BAENSCH, U. Blooming bromeliads. Nassau: Tropic Beauty, 1994. 269p.

BASE DE DADOS TROPICAL. Banco de espécies da BDT. Disponível em: <http://www.bdt.fat.org.br/species>. Acesso em: 27 ago.2001.

BECKERMAN, J. Salt damage. Yard \& Garden Line News, v.7, n.1, 2005. Disponível em: http:// www.extension.umn.edu/yardandgarden/YGLNews/ YGLN-Jan0105.html\#salt. Acesso em: 17 fev.2005.

BENZING, D. H., HENDERSON, K., KESSEL, B., SULAK, J. The absorptive capacities of bromeliad trichomes. American Journal of Botany, Columbus, v.63, n.7, p.1009-1014, 1976.

BENZING, D. H., RENFROW, A. The nutritional dynamics of Tillandsia circinnata in Southern Florida and the origin of the "air plant" strategy. Botanical Gazette, Chicago, v.141, n.2, p.165-172, 1980.

BROMELIAD SOCIETY INTERNATIONAL. Bromeliad info. Disponível em: <http://bsi.org/>. Acesso em: 17 fev. 2005 .

BROMELIA. Instructions for growing bromeliads. Disponível em: <http://www.bromelia.com/ cultuur.html\#4>. Acesso em: 26 mai.2005.

CITES. Convention on International Trade in Endangered Species of Wild Fauna and Flora. Disponível em:<http://www.cites.org/eng/disc/ what_is.shtml>. Acesso em: 8 ago.2001.

D'ANDRÉA, J. C.; DEMATTÊ, M. E. S. P. Effect of growing media and fertilizers on the early growth of Aechmea fasciata Bak. Acta Horticulturae, Leuven, v.511, p.271-276, 2000.

DEMATTÊ, M. E. S. P. Cultivo de Tillandsia gardneri Lindl. y Tillandsia stricta Sol. en macetas: comparación de substratos. In: MASCARINI, L.; VILELLA, F.; WRIGHT, E. (Ed.). Floricultura en la Argentina: investigación y tecnología de producción. Buenos Aires: Editorial Facultad Agronomía, Universidad de Buenos Aires, 2003. p.165-172.
FLOWER, A. Notes on growing bromeliads from seed. Disponível em: <http://anwyl.com/articles/ growing\%20from\%20seed.htm> Acesso em: 17 fev.2005.

JARDIM DE FLORES. Bromélias. Disponível em: http:/ / ww w.jardimdeflores.com.br/floresefolhas/ A11bromelia.htm. Acesso em: 13 fev.2005.

KÄMPF, A. N. Aspectos da nutrição de bromeliáceas epífitas. In: CONGRESSO BRASILEIRO DE FLORICULTURA E PLANTAS ORNAMENTAIS, 4., 1983, Rio de Janeiro. Anais... Brasília: Embrapa, 1984. p.187-198.

PAULA, C. C. de; SILVA, H. M. P. da. Cultivo prático de bromélias. 2.ed. Viçosa: UFV, 2001. 73p.

PEREIRA, E. Species novae in Brasilia Bromeliacearum - VII. Bradea, Rio de Janeiro, v.1, p.437-439, 1974.

PINTO, A. C. R., DEMATTÊ, M. E. S. P., PAVANI, M. C. M. D. Composição florística de epífitas (Magnoliophyta) em fragmento de floresta do município de Jaboticabal, SP, Brasil. Científica, São Paulo, v.23, n.2, p.283-289, 1995.

PINTO, A. C. R.; DEMATTÊ, M. E. S. P.; PAVANI, M. C. M. D. Levantamento de espécies arbóreas hospedeiras de epífitas pertencentes à Divisão Magnoliophyta, em fragmento de floresta no município de Jaboticabal, SP, Brasil. Ecossistema, Espírito Santo do Pinhal, v.19, p.136148, 1994.

RESOLUÇÕES. Resolução No 278, de 24 de maio de 2001. Disponível em: <http://www.mma.gov.br/port/ conama/res/res01/res27801.html>. Acesso em: 15 fev.2005.

SCHUBERT, T. S. Epiphytic bromeliads on Florida trees. Florida Department of Agriculture and Consumer Service, 1990. 2p. (Plant Pathology Circular, 333).

SILVA, M. C.; COUTINHO, C. E. A beleza exótica das orquídeas e bromélias de Roberto A. Kautsky. Vitória: M\&M Publicidade e Promoções, 1999. p.116-117. SOCIEDADE BRASILEIRA DE BROMÉLIAS. Cultivo. Disponível em: <http://www.bromelia.org.br/cultivo.htm>. Acesso em:13 fev.2005.

UNESP. Campus de Jaboticabal. Estação Agroclimatológica. Valores médios do período 19712000. Disponível em < http://www.fcav.unesp.br/ Departamentos/exatas/estacao/normal.htm>. Acesso em: 30 abr.2004. 